\title{
Knowledge and experience of young people regarding drug abuse between 1969 and 1979
}

\author{
J D WRIGHT, L PEARL
}

\begin{abstract}
A trend survey carried out by anonymous questionnaire of the knowledge and experience of drug abuse among fourth-year pupils in three Wolverhampton secondary schools in 1969, 1974, and 1979 showed familiarity with the names of drugs, but that there continues to be considerable ignorance and misunderstanding about how drugs are taken and their dangers. Contact with drugs and drug-taking increased over the first five years, but this trend was not continued through to 1979. Television remained the most important source of information about drugs, while peer group and social pressures remained the most important reason for starting to take drugs.
\end{abstract}

Effective preventive measures must include a health education programme that discusses decision-making processes and a wider view of "drugs in society."

\section{Introduction}

"The teacher likes it when the kids are high on marijuana because they just sit there and don't disrupt the class." This statement was made by a community worker in down-town Boston to one of us (JDW) while on a recent visit to the United States and Canada. In a country where officially quoted statistics $^{1}$ state that one in 500 of the population use heroin daily, one in 22 have used cocaine, and one in five cannabis, there is deep concern about the extent of drug taking by young people. Drug taking in Britain by young people increased during the mid-to late 1960s but appeared to level out in the mid-1970s. Although the average age of registered opiate addicts has risen, it is a matter of concern that Home Office statistics ${ }^{2}$ show that, in the past few years, the notifications of opiate addicts, the number of convictions for drug offences, and the number and weight of drug seizures have increased.

By 1969 , at the time of the first survey, it had become clear that, as most young people were hearing about drugs, it was essential to discuss drugs in a health education programme in secondary schools. The first survey was carried out to gain factual information about what young people in Wolverhampton knew about the subject, so that a realistic health education

\footnotetext{
Wolverhampton Area Health Authority, St John's Square, Wolverhampton WV2 4DB

J D WRIGHT, MB, MFCM, specialist in community medicine

The Polytechnic, Wolverhampton

L PEARL, BSC, DPHIL, principal lecturer in statistics
}

programme could be planned. The repeat survey in 1974 reported appreciable changes in the knowledge and experience of these young people. ${ }^{3}$

Changes in society, the "pop scene," medical and legal practice, and mass media coverage have all influenced young people's knowledge and experience of drug taking. The present survey continues to examine the effects of these influences.

\section{Method of the survey}

In order that valid comparisons could be made the format of the 1979 survey was a repeat of that carried out in 1969 and 1974. The three comprehensive schools were situated, both geographically and socially, in different parts of the town. The character of the three comprehensive schools has, in general, remained the same. The total sample of 648 fourth-year pupils (aged 14 and 15) included slightly more boys than girls and was of mixed ability with a bias towards the lower end of the ability range.

The survey was carried out by ourselves and three assistants, using a questionnaire (see figure) that included a mixture of open-ended and ticked replies. Before visiting the school no indication of the survey was given to the pupils. The school staff were excluded throughout, and it was explained that this was an anonymous, confidential survey being carried out as part of a research project into drug education. After completion, a $10 \%$ random sample were interviewed, and there was no evidence that the pupils had misunderstood the questionnaire. Where there were sufficient respondents, Chi-squared tests were used to compare proportions between years, and $p$ values have been reported where appropriate.

\section{Results}

Roughly similar proportions, $93 \%$ in $1969,86 \%$ in 1974 , and $92 \%$ in 1979 , replied to the question, "What drugs taken by addicts do you know ?" (Hereafter, whenever comparisons are made in the text, the percentages will be listed in the year order 1969, 1974, and 1979). The drug most often mentioned in 1969 and 1974 was cannabis, as compared to opiates in 1979. Table I gives details of the frequencies with which drugs were mentioned. This table also shows percentages of pupils who could correctly specify how the drugs that they had mentioned were taken.

An increasing proportion answered the question, "What dangers do you know of these drugs?" Despite this increase in 1979, as in previous years, their replies showed considerable ignorance and misunderstanding of the effects (table II).

Almost the whole sample, $454(97 \%)$ in $1969,515(99 \%)$ in 1974, and $641(99 \%)$ in 1979 answered the question, "Do you personally know anyone taking drugs ?" The percentages of positive replies were $15 \%, 23 \%, 21 \%$, the increase between 1969 and 1974 being statistically significant $(p=0.002)$. For the 25 pupils in 1969 who mentioned which drug was being taken, the rank order was amphetamines, $64 \%$; opiates, $28 \%$; cannabis, $25 \%$; lysergide, $8 \%$; in 1974, (36 replies) cannabis, $81 \%$; amphetamines, $31 \%$; lysergide, $17 \%$; opiates, $14 \%$; barbiturates, $6 \%$; and in 1979 (94 replies) cannabis, $76 \%$; opiates, 


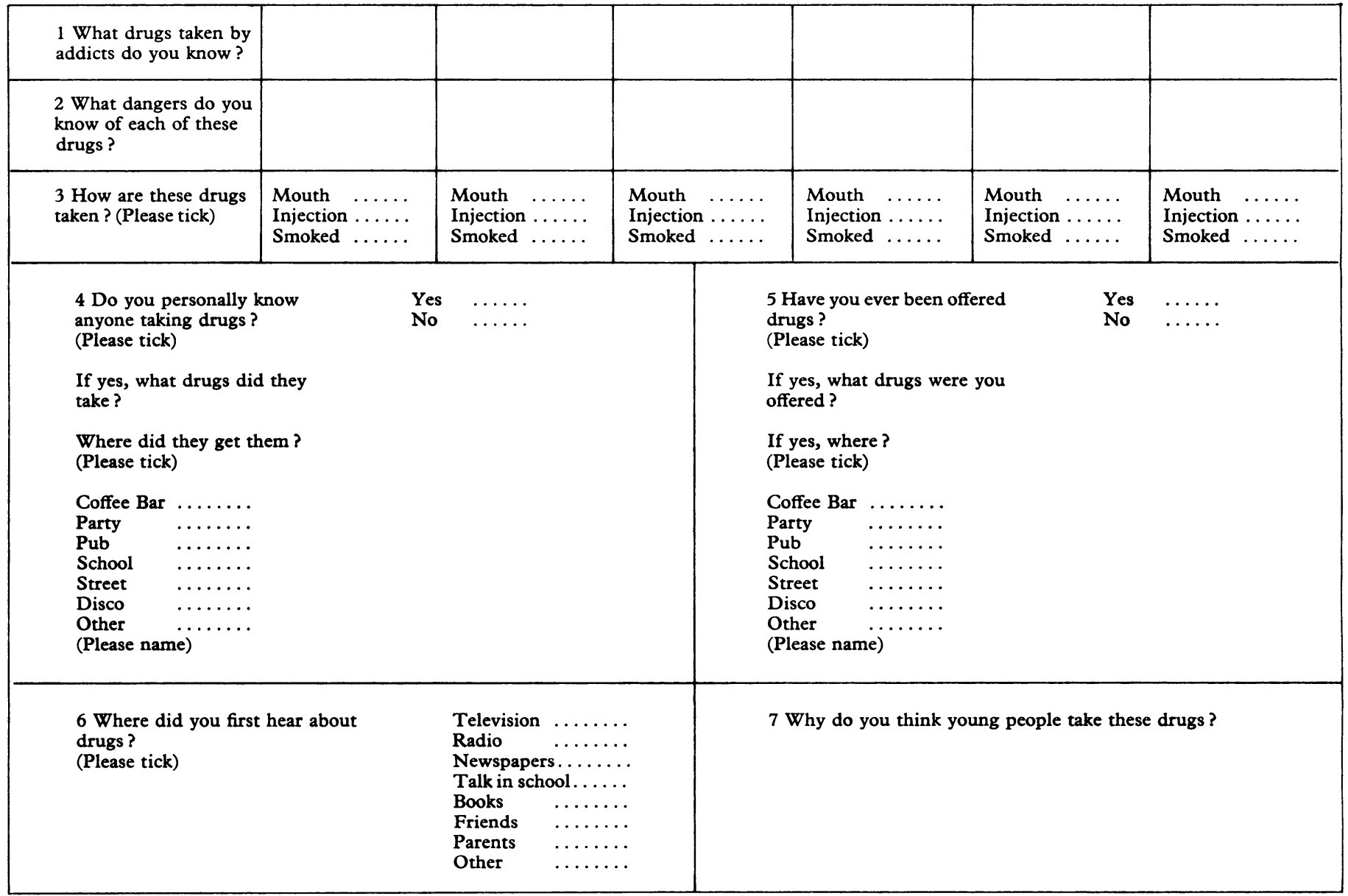

Questionnaire on drug dependence.

TABLE I-Details of the frequencies with which drugs were mentioned

\begin{tabular}{|c|c|c|c|c|c|c|}
\hline & \multicolumn{3}{|c|}{$\begin{array}{l}\text { Replies to question: } \\
\text { What drugs taken by addicts do you } \\
\text { know? }\end{array}$} & \multicolumn{3}{|c|}{$\begin{array}{l}\text { Replies to question: } \\
\text { How are these drugs taken ?* }\end{array}$} \\
\hline & $\begin{array}{l}1969 \\
\%(\mathrm{No})\end{array}$ & $\begin{array}{l}1974 \\
\%(\mathrm{No})\end{array}$ & $\begin{array}{l}1979 \\
\%(\mathrm{No})\end{array}$ & $\begin{array}{l}1969 \\
\%(\mathrm{No})\end{array}$ & $\begin{array}{l}1974 \\
\%(\mathrm{No})\end{array}$ & $\begin{array}{c}1979 \\
\%(\mathrm{No}) \\
\end{array}$ \\
\hline $\begin{array}{l}\text { Opiates } \\
\text { Cannabis } \\
\text { Cocaine } \\
\text { Lysergide } \\
\text { Barbiturates } \\
\text { Amphetamines } \\
\text { Solvents } \\
\text { Mandrax }\end{array}$ & $\begin{array}{l}91(391) \\
98(425) \\
15(61) \\
87(351) \\
1(4) \\
44(196) \\
0(0) \\
0(0)\end{array}$ & $\begin{array}{l}70(314) \\
84(380) \\
19(86) \\
49(219) \\
8(35) \\
14(65) \\
0(0) \\
0 \cdot 4(2)\end{array}$ & $\begin{array}{l}83(495) \\
75(448) \\
50(299) \\
32(190) \\
10(57) \\
8(46) \\
8(50) \\
0.2(1)\end{array}$ & $\begin{array}{l}48(188) \\
76(325) \\
0(0) \\
44(154) \\
0(0) \\
89(175) \\
0(0) \\
0(0)\end{array}$ & $\begin{array}{l}66(207) \\
81(309) \\
55(47) \\
38(83) \\
60(21) \\
80(52) \\
0(0) \\
100(2)\end{array}$ & $\begin{array}{l}79(392) \\
82(368) \\
57(169) \\
32(61) \\
89(51) \\
80(37) \\
18(9) \\
0(0)\end{array}$ \\
\hline $\begin{array}{l}\text { Total No in sample } \\
\text { No who replied } \\
\text { Percentage who replied }\end{array}$ & $\begin{array}{r}471 \\
439 \\
93\end{array}$ & $\begin{array}{r}523 \\
450 \\
86\end{array}$ & $\begin{array}{r}648 \\
598 \\
92\end{array}$ & $\begin{array}{r}471 \\
439 \\
93\end{array}$ & $\begin{array}{r}523 \\
437 \\
84\end{array}$ & $\begin{array}{r}648 \\
597 \\
92\end{array}$ \\
\hline
\end{tabular}

*Correct replies to question 3 are expressed as a proportion of those who mentioned the drug in question 1.

$13 \%$; amphetamines, $13 \%$; diphenhydramine/methaqualone (Mandrax), $5 \%$; lysergide, $3 \%$; barbiturates, $2 \%$; cocaine and solvents, both $1 \%$. For the 50 who in 1969 mentioned where the drugs were obtained, the rank order was party, $34 \%$; coffee bar, $32 \%$; pub, $14 \%$; school, $12 \%$, in 1974 (83 replies) party, $25 \%$; street, pub, and school, all $12 \%$; coffee bar, $6 \%$; disco, $5 \%$; and in 1979, (104 replies) party, $31 \%$; disco, $28 \%$; street, $26 \%$; pub, $18 \%$; school, $13 \%$; coffee bar, $5 \%$.

Almost the whole sample, 462 (98\%), 514 (98\%), 641 (99\%), answered the question, "Have you ever been offered drugs?" The proportion of positive replies increased significantly from $5 \%$ to $10 \%$ between 1969 and $1974(p=0.02)$ but remained at $10 \%$ in 1979 . In the replies from the 11 pupils who in 1969 mentioned which drug had been offered, cannabis and amphetamines featured equally. In 1974, for the 23 replies, the rank order was cannabis, $56 \%$; amphetamines,
$22 \%$; opiates, $17 \%$; both barbiturates and lysergide, $4 \%$ and in 1979 (44 replies) cannabis, $82 \%$; amphetamines, $14 \%$; opiates, $7 \%$; barbiturates, $5 \%$; solvents, $5 \%$; cocaine, $2 \%$. For the 22 pupils who in 1969 mentioned where the drug was offered, the rank order was party, $41 \%$; school, $27 \%$; street, $14 \%$; in 1974 (34 replies) party, $47 \%$; street, $32 \%$; school, $18 \%$; disco and pub, both $9 \%$; coffee bar, $6 \%$; and in 1979 (49 replies) disco, $47 \%$; street, $43 \%$; party, $24 \%$; school, $16 \%$; pub, $8 \%$; coffee bar, $2 \%$.

In all three survey years there was a good response to the question, "Why do you think young people take these drugs ?" (table III).

Almost the whole sample $(98 \%, 99 \%, 99 \%)$ replied to the question, "Where did you first hear about drugs?" The questionnaires were completed before the pupils had received any formal health education on the subject. Over the ten years, television has remained the predominant source of information $(75 \%, 73 \%, 71 \%)$, whereas news- 
TABLE II-Replies to question: What dangers of these drugs do you know? (Percentages are of the total who mentioned each drug as shown in table I)

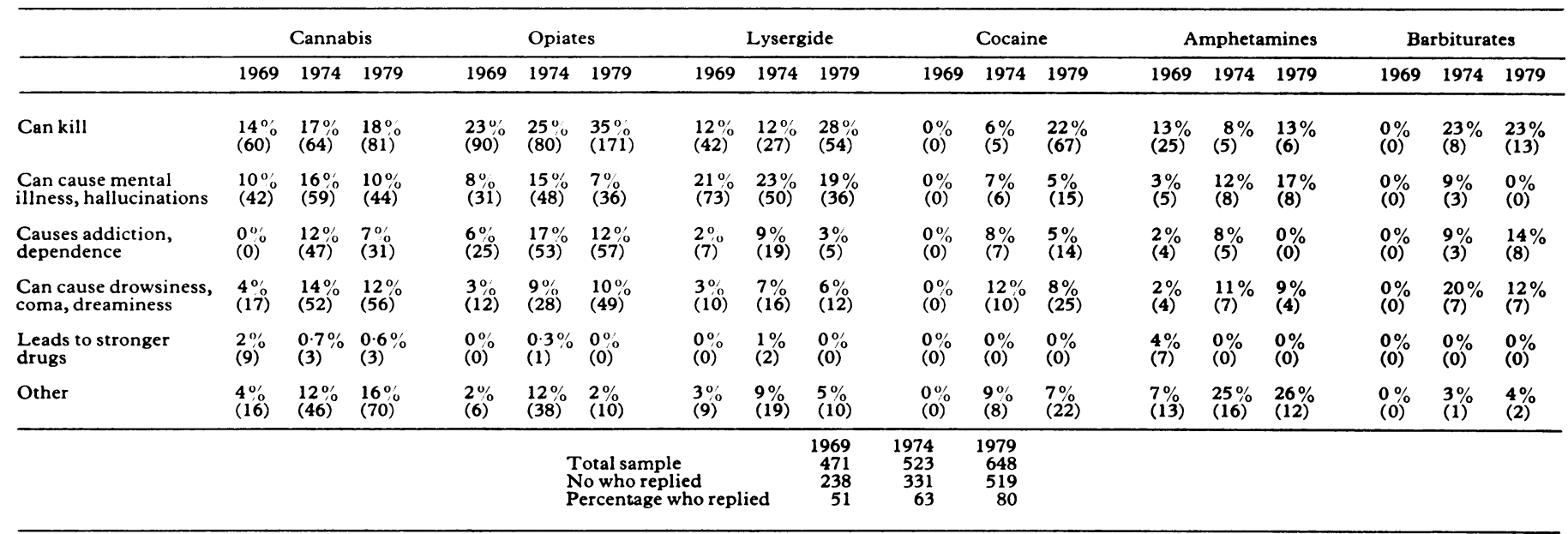

TABLE III-Replies to question: Why do you think young people take these drugs?

\begin{tabular}{lccc}
\hline & $\begin{array}{c}1969 \\
0(\mathrm{No})\end{array}$ & $\begin{array}{c}1974 \\
\%(\mathrm{No})\end{array}$ & $\begin{array}{c}1979 \\
\%(\mathrm{No})\end{array}$ \\
\hline To feel big, show off, grown-up & $29(123)$ & $30(145)$ & $34(214)$ \\
For kicks, fun, to feel good & $21(90)$ & $22(106)$ & $22(136)$ \\
To calm nerves & $0(0)$ & $11(53)$ & $21(133)$ \\
Because friends do, trendy & $39(163)$ & $25(122)$ & $19(116)$ \\
To relieve boredom, depression & $6(24)$ & $18(85)$ & $18(111)$ \\
To escape problems, reality & $19(81)$ & $20(98)$ & $14(86)$ \\
For the experience, curiosity, sensation & $32(134)$ & $13(61)$ & $13(78)$ \\
\hline Total No in sample & 471 & 523 & 648 \\
No who replied & 425 & 480 & 621 \\
Percentage who replied & 90 & 92 & 96 \\
\hline
\end{tabular}

papers have become less important sources of information $(45 \%$, $28^{\circ}, 23^{\circ}$ o). Other sources of information mentioned in the 1979 rank order were friends $(12 \%, 10 \%, 15 \%)$, parents $(7 \%, 15 \%, 14 \%)$, talk in school $(0 \%, 17 \%, 11 \%)$, radio $(11 \%, 6 \%, 7 \%)$, and books $(0 \%$, $\left.9^{\circ}, 5^{\%}\right)$

\section{Discussion}

Since 1969 several relevant changes relating to the drug "scene" have taken place in society, in medical practice, and in the coverage of the subject by the mass media. Society now has a more realistic attitude to drug taking by young people in general and to cannabis in particular. In the late 1960 s attitudes to drug taking were strongly influenced by the pop culture-for example, by the lives and lyrics of the Beatles and the Rolling Stonesbut since then, the trend, to some extent, has been more anti than pro drug taking.

Many areas in Britain, including Wolverhampton since 1971, have introduced a voluntary limitation on the prescribing of amphetamines. Consequently, the number of prescriptions has decreased $^{4}$ and the availability of amphetamines through thefts from chemist shops has been reduced. Unfortunately, this source has been replaced by the illicit production of amphetamine sulphate. Chemist shops remain, through theft, a major source to the black market of barbiturates (still prescribed by a few doctors) and opiates (dipipanone (Diconal) being one of the commonest). The present official controlled-drugs cabinet has two serious defects; firstly that, being white, it is easily identifiable and, secondly, it is easily prized open. Improved security in chemist shops could considerably reduce the amounts of therapeutic drugs reaching the black market.

Coverage of drug taking by the mass media has also changed. The glamorous and dramatic headlines in the late ' 60 s gave way to a more responsible and low-key approach in the late ' $70 \mathrm{~s}$. It is of concern, however, that during 1980 press coverage increased and, in the local press in particular, solvent sniffing ${ }^{5}$ received widespread and undesirable publicity. From the mid1970s, the harmful social and medical consequences associated with alcohol have quite rightly featured more prominently. The underground press and the "grapevine" have, over the years, also indicated to young people that drugs, for example, lysergide, may have unpleasant and harmful effects. It is against this background that the changes we report must be set. In general it is interesting that the results presented reflect these wider changes over the ten years.

\section{KNOWLEDGE ABOUT DRUGS}

Pupils' familiarity with the names of drugs has changed over the ten years, which can to some extent be explained by the changes in press coverage and in the availability of drugs. The increased availability on the black market of some drugs is reflected by their being more often mentioned-for example, cocaine, barbiturates, and, highly importantly, solvents, which were mentioned for the first time in 1979 by $8 \%$ of the pupils. The decreased availability of amphetamines is reflected by their being less frequently mentioned. The decreasing awareness by the pupils of lysergide is probably associated with decreasing availability and press coverage. This latter factor would appear to be the more important influence relating to the less frequent mention of cannabis, since its availability has not decreased.

\section{EXPERIENCE OF DRUG TAKING}

Based on the studies of various researchers ${ }^{0-10}$ over the period 1967-73, it may reasonably be inferred that there was an increasing prevalence over that period. The indication from the present three surveys is that there was increasing exposure to, and taking of, drugs at the end of the 1960s and in the early part of the 1970s, but that this tendency has not continued. Of the drugs taken by acquaintances and being offered to the respondents, cannabis, over the ten years, has replaced amphetamines as the most frequently mentioned drug. In the present study cocaine and solvents were first mentioned in 1979 in this context. The survey of the Institute for the Study of Drug Dependence in $1973^{\circ}$ ranked the drugs mentioned by drug takers as cannabis, sedatives, stimulants, lysergide, and heroin.

In 1979 the two places most often mentioned as the source of drugs taken by acquaintances were parties and discos. Discotheque and street were the two most frequently mentioned places where drugs were offered. The trends across the years for the most part reflect changes in society-for example, the decrease 
in popularity of coffee bars and the increasing popularity of discotheques. Some authors ${ }^{3}{ }^{8}{ }^{9} \mathrm{emphasise}$ parties and pubs as a source. Most young people are introduced to drugs by people they know, rather than by strangers. Schools appear to continue over the ten years to be a less important place where drugs are offered.

Sporadic outbreaks of solvent sniffing have been reported ${ }^{11}$ in Britain, and the anxiety is that these substances are so easily available. It is of concern that, in $1979,8 \%$ of the pupils were aware of solvent sniffing, but surprisingly only 10 of the 50 who mentioned solvents knew how they were taken or had ideas of their dangers.

Although the experience of drug taking of most young people in Britain is minimal compared with the United States and Canada, the size and extent of their problems are a salutary warning. The survey of Lloyd Johnston et $a^{12}$ in 1978 of high school seniors (aged 15-18) found that 59\% had used marijuana at least once, $14 \%$ hallucinogens (including phencyclidine, $13 \%$ cocaine, and $12 \%$ inhalants. The Addiction Research Foundation in Toronto, in their report ${ }^{13}$ of drug use among $586211-18$-year-olds in 104 Ontario schools in 1977, showed that, over the whole sample, $25 \%$ had used cannabis, $10 \%$ solvents, $6 \%$ barbiturates (non-prescribed), 10\% stimulants (non-prescribed), 2\% heroin, 11\% hallucinogens (including lysergide), and 4\% cocaine. In those aged 14-15 use was extensive-cannabis $22 \%$, solvents $11 \%$, barbiturates $7 \%$, heroin $2 \%$, stimulants $12 \%$, hallucinogens $9 \%$, and cocaine $4 \%$.

\section{REASONS FOR DRUG TAKING}

These pupils, predominantly non-drug takers themselves, mentioned "to feel big, show off, grown up" as the most important reason for taking drugs. Another reason given, "because friends do" (fourth in rank order in 1979, though less important than in previous years) supports the view of the other studies $^{9} 101415$ that young people start taking drugs primarily because of social and group pressures. One American study (W J Bukowski, paper presented at the Annual Conference of the American Public Health Association, 4-6 November 1979) comments on "the correlation between drug abuse and psychosocial factors such as a low self-concept, high levels of rebelliousness, and family disorganisation." Clearly drug taking is influenced by multiple aetiological factors.

Interestingly "to calm nerves, to feel peace" has increased significantly as a reason for taking drugs, from being mentioned in 1969 by no respondents to $11 \%$ in 1974 and $21 \%$ in 1979. Does this group of young people see drugs increasingly as a way to cope with stress and boredom (a reason given by $6 \%$ in 1969 and 1974 and by $18 \%$ in 1979) ? The fact that only $13 \%$ in 1979 and 1974 , as compared with $32 \%$ in 1969 , mentioned "for the experience, curiosity" may reflect the reduced press coverage in recent years and that drug taking is now nothing new.

\section{SOURCES OF INFORMATION ABOUT DRUGS}

Over the three survey years, television remained the most important source of information, with newspapers ranking second. The most helpful approach by the mass media would be to give minimal or no coverage. This particularly applies at the present time to any publicity about solvent sniffing, since the agents are so easily available to children of any age. Over the ten years, discussion by parents and in schools has taken on a more important role. There is a continuing need to educate parents and teachers so that they can have more informed discussions with young people. A positive attitude by the parents may help a young person to resist the peer group pressure to take drugs.

Several studies ${ }^{14-18}$ have critically discussed the aims, types, and effectiveness of drug education. Clearly from these studies and our own research effective preventive measures must include vigorous health education programmes that take account of the following points:

(1) The drugs of abuse (excluding solvents unless there is a problem in the school) should be discussed in the context of the place of "drugs in society," which includes discussion of alcohol, tobacco, and medicines.

(2) Drug education must be part of a wider and positively orientated health education programme.

(3) In the words of the UNESCO report, "the aim of drug education programmes should be to encourage better informed personal judgments based on improved and accurate information and improved knowledge about decision-making processes."'18

We acknowledge the invaluable help given by $\mathrm{Mr} \mathrm{J}$ W Urwin, Mr M A Kelk, and, in particular, by Mrs W B Henshaw and Mrs L J Wilson.

\section{References}

1 Strategy Council on Drug Abuse. Federal strategy for drug abuse and drug traffic prevention. Washington DC: US Government Printing Office, 1979.

2 Home Office. Statistics of the misuse of drugs in the United Kingdom. London: Home Office, 1979. (Statistical Bulletin issue 11/80.)

${ }^{3}$ Wright JD. Knowledge and experience of young people regarding drug abuse between 1969 and 1974. Medical Science and the Law 1976;16: 252-63.

4 Institute for the Study of Drug Dependence. UK official statistics relating to drug abuse-supplement to Druglink No 13. London: ISDD, 1980.

s Institute for the Study of Drug Dependence. Sniffing debate in Parliament, London: ISDD, 1980. (Druglink No 14, 12-3.)

6 Wiener RST. Drugs and school children. London: Longman, 1970.

${ }^{7}$ Hindmarsh I. The pattern of drug abuse among school children. Bull Narc 1972;24:23-6.

${ }^{8}$ Ritson EB, Toller P, Harding F. Drug abuse in the East Midlands-a study of 139 patients referred to an addiction unit until 1969/70. Br $\mathcal{F}$ Addict 1973;68:65-71.

- Dorn N, Thompson A. Evaluation of drug education. London: Institute for the Study of Drug Dependence, 1974.

${ }^{10}$ Fish F, Wells DWP, Bindeman S, Bunney JE, Jordan MM. Prevalence of drug misuse among young people in Glasgow 1970-2. BrF Addict 1974: 69:343-56.

11 Watson J. The growing problem of glue sniffing. Social work today. Vol 8. No 3. London: W Hill, 1976.

12 Johnston LD, Bachman JG, O'Malley PM. Drugs and the class of '78: behaviors, attitudes, and recent national trends. Rockville, Maryland: National Institute on Drug Abuse, 1979.

${ }^{13}$ Smart RG, Goodstadt MS, Sone IJ. Alcohol and drug use among Ontario students in 1977. Toronto: Addiction Research Foundation, 1977.

14 Plant A. Drugtaking and prevention: the implications of research for social policy. $B r \mathcal{F}$ Addict $1980 ; 75: 245-54$.

15 Swinson RP, Eaves D. Alcoholism and addiction. Estover: Macdonald \& Evans Ltd, 1978.

17 Dorn N. Teaching decision-making skills about legal and illegal drugs. London: Institute for the Study of Drug Dependence, 1977.

18 United Nations Educational, Scientific, and Cultural Organisation. Meeting of experts on the co-ordination of school and out-of-school education concerning the problems associated with the use of drugs: Working Paper-trends in drug use and preventive education in industrialised countries, Lisbon, Portugal, 8-12 September 1980. Paris : UNESCO, 1980:1-30.

(Accepted 9 December 1980)

A girl of 15 has been fully investigated by thoracic and cardiac physicians for an intractable cough that requires linctus codeine $5 \mathrm{ml}$ four times a day (15 mg codeine phosphate to $5 \mathrm{ml}$ ) to control. Without this her life would be quite miserable. Is there any contraindication to long-continued use?

I am not aware of any serious long-term effects of codeine. Dependence may occur but is unlikely with this dose. ${ }^{1}$ The long-term use of codeine linctus for an undiagnosed cough in a 15 year old however cannot be considered satisfactory. Every attempt should be made to find the cause so that more appropriate treatment may be given. In particular the possibility of psychological factors should be considered, especially if the cough is present only during the day.

'Dukes MNG, ed. Meyler's side effects of drugs. 9th ed. Amsterdam: Excerpta Medica, 1980:110. 